\title{
Design Smart Attendance laverging People Identification System as Service Using SoaML for Smart Campus
}

\author{
Iwan Setiawan \\ School of Electrical Engineering and Informatics \\ Institut Teknologi Bandung \\ Bandung, Indonesia \\ iwan-setiawan@student.itb.ac.id
}

\begin{abstract}
One feature of smart campus is the identification of people[1]. This feature serves to record civitas data and guests who enter the campus for the purpose to monitor the university. This feature is very important and needs further research to be developed. In this research will be designed people people system that can be used for various purposes by all sectors in the university who need this system. This will become clearer in this study.
\end{abstract}

Keywords-Smart Attendance; SoAML

\section{INTRODUCTION}

The development of information and communication technology (ICT) continues to increase along with researches that have been implemented to meet the needs of more advanced technology as a solution to problem solving. This affects the changing of conventional technology into digital that happens everywhere, not least in the university environment as the education sector. Intelligence technology is implemented to make the features of the university to be smart and that is what is called smart campus. The term smart campus has been widely used in research [1], [2]. he word 'smart' shows the ability of an object that has been implanted with intelligence in it.

Many features must be owned by the university to realize smart campus. One of them is people identification. This feature is very important for universities to improve academic performance when applied to the presence of academic community such as students, lecturers, and employees in the university environment. However, for the implementation of people identification for attendance requires further research to create a design of smart attendance services that have high interoperability. For this reason, this research is done by focusing on proposing people identification design for smart attendance with Service Oriented Architecture approach [3] and the service system model is made with SoaML With SOA approach and model with SoaML system will be easily improved and developed.

\section{RELATED WORD}

\section{A. Attendance Management System System}

Related research on attendance system is done with various approach of device selection to support smart attendance system. As in the research attendance management system that uses two device selection selection to determine the performance and efficiency [4]. Another study of attendance focuses on the attendance approach by combining room access with the presence of people entering the room using fingerprint sensors [5]-[7] as well as backups of keypads at each entrance space [8].

Devices and technologies used in attendance systems in these studies make attendance systems intelligent so they can be called smart attendance [9] or intellegence attendance [10].

\section{B. SoaML}

Several studies have used SoaML to model service systems as in research with the results of water management service modeling and warnings using SoaML [11] and research on modeling development for smart grid services with SoaML [10], [12], [13]. SoaML introduces new terminology. An important element is the capability, as a set of functions related to a service, which may be defined in the inception phase of the life cycle. The capability may be exposed by multiple service interfaces. SoaML extends the concept of collaboration, existing in the Unified Modeling Language. It uses it for presenting service contracts and for the global presentation of the services architecture. The participants to collaboration may be providers and consumers of services. Details about services may be introduced as interface operations, ports that connect participants, and channels for communicating between ports.

Based on related research, in this study will make the model of smart attendance system proposed using SoaML. This system can support the tool ayang will be used for identification such as RFID, smart card [14] and fingerprint. 


\section{METHODOLOGY}

The methodology used in this study is the Service Computing Software Engineering Framework (SCSEF) [5]. This framework can be used as a methodology to process the service process and service system. So the framework is suitable for use in this study because the object of this study discusses the engineering of people identification system into a service that is smart attendance. This framework provides guidance on building and realizing the Service Computing System. SCSEF consists of five stages: Objective and Requirements, Modeling, Development, Deployment, and Evaluation. For more details can be seen in figure 1. However, as a preliminary study, this study limits the stage up to modeling. The next three stages will be done in subsequent research..

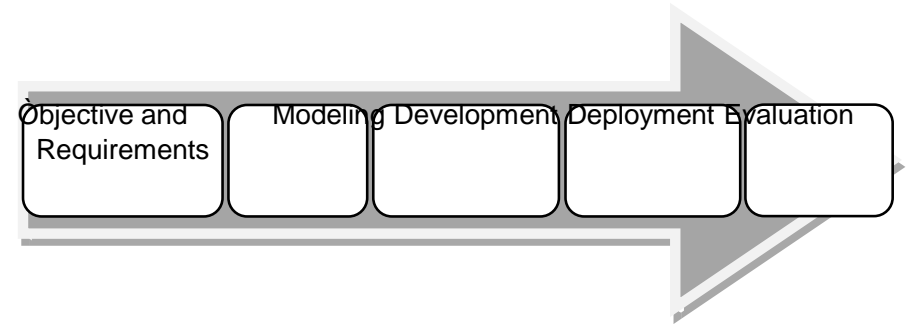

Figure 1 SCMEF

\section{RESULT AND DISCUSSION}

\section{A. Objective and Requirements}

One of the main tasks of the academic administrative unit is to manage the attendance of students and lecturers in every lecture activity. In the implementation of the task there are still many universities that have not used technology to create an intelligent presence system. The presence of students and lecturers in the classroom is still done conventionally using paper. Research is conducted by identifying existing process businesses for attendance processes.

Student attendance is done by filling out the attendance forms form. Students sign the attendance list and lecturers fill out the course news (BAP). The attendance list is staffed by academic administrative officers. The attendance $\log$ is inputted into an existing system. Functions in the system will perform calculations to calculate the percentage of student attendance of each course. Similarly, it is done with BAP. These processes can be seen in Figure 2.

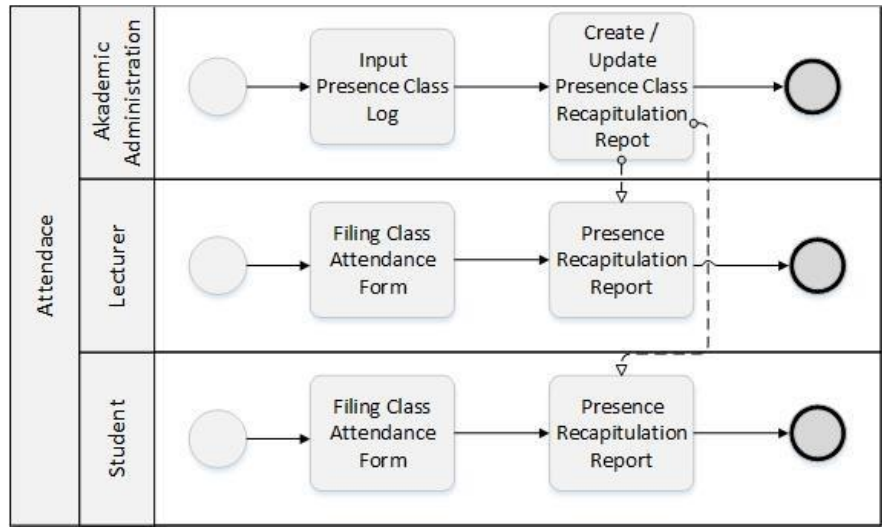

Figure 4 Attendance BPMN As-Is

\section{B. Modeling}

The first thing in the design stage is to improve the existing service business by adding services as innovation. This can be done by comparing the as-is business process with the to-be business prosess. The gap between the two business processes can be used as a service innovation. The following is a business process diagram that illustrates the proposed improvement as an innovative smart attendance service.

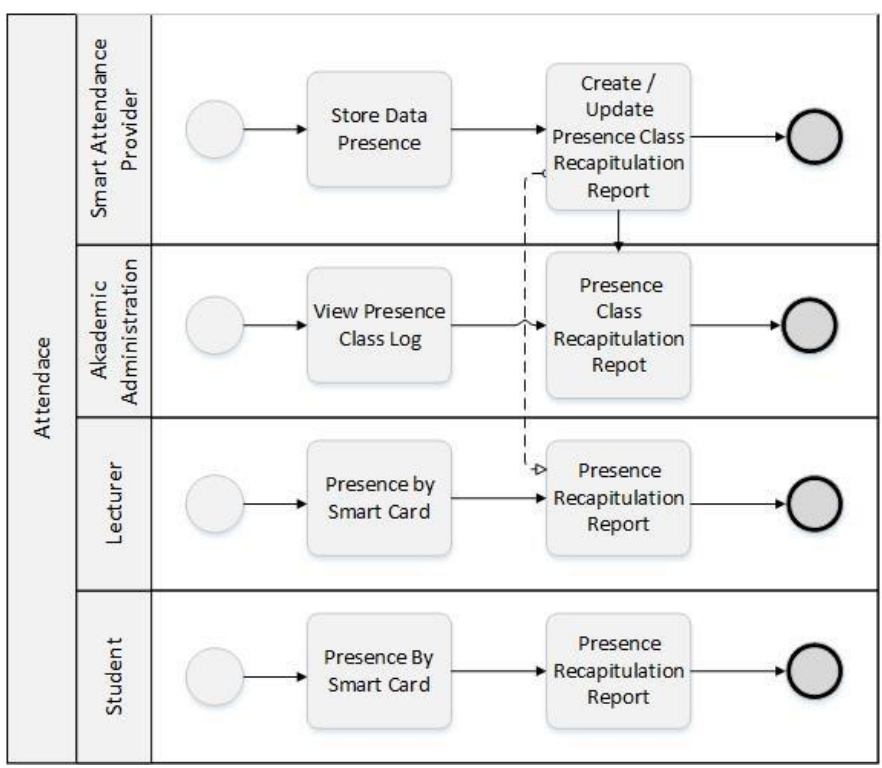

Figure 3 Attendance BMPN To-Be

Figure 4 describes the identification services associated with samart attendance. Because the data lecturer and student data is part of the civitas data that exist in the database identification provider. Then the identification service is also described in this study. 


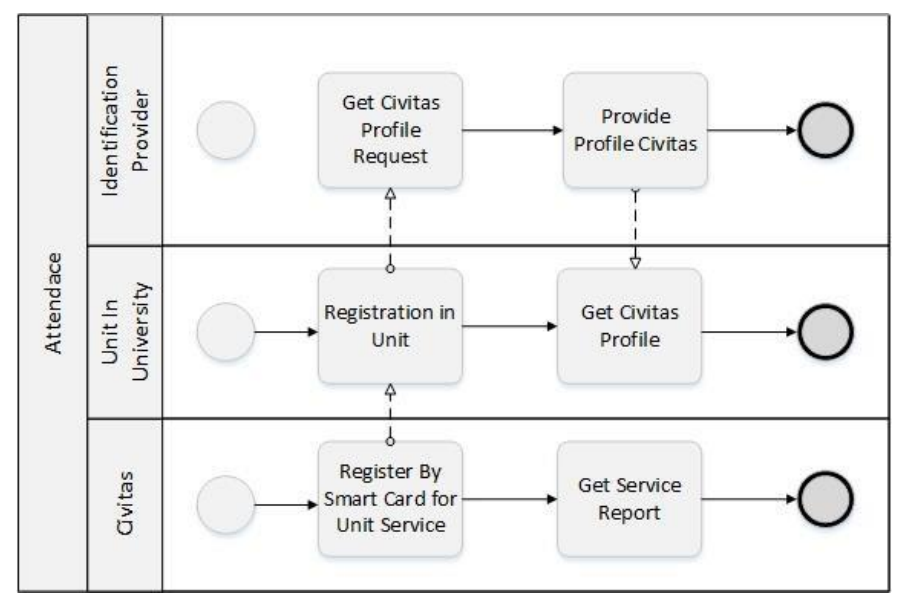

Figure 4 Identification BMPN To-Be

Service innovation can be determined through tables based on comparison between existing processes in as-is and marked tobe. A process that does not exist in Business proces as -is is a service innovation proposed to be developed. Here is a table created to describe the gaps of existing processes in as -is and to-be to define the service innovations that will be modeled. The proposed model is used as a basis for development at a later stage of the SCSEF stages.

\begin{tabular}{|c|c|c|c|}
\hline \multirow{3}{*}{ No } & & & \\
\hline & \multirow{2}{*}{ Process } & \multicolumn{2}{|c|}{ Business Process } \\
\hline & & $A s-I s$ & To-Be \\
\hline 1 & $\begin{array}{l}\text { Presence by smart card (scanning ID } \\
\text { Card) }\end{array}$ & & $\checkmark$ \\
\hline 2 & $\begin{array}{l}\text { Identification Service for rgistration in } \\
\text { unit }\end{array}$ & & $\checkmark$ \\
\hline
\end{tabular}

Figure 5 describe Sequency diagram identification for attendance, provider as Identification Collector and consumer as identification Placer.

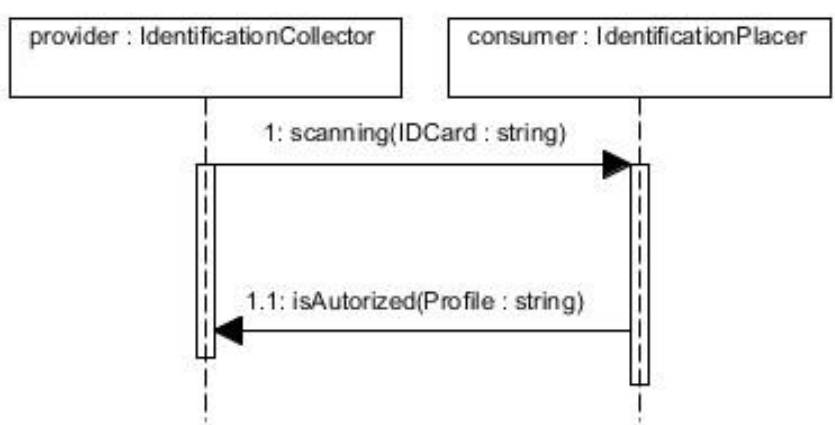

Figure 5 Sequence diagram tapping Smart Card for Identification

Figure 6 describes the service interface diagram of the identification service used by the attendance service. The interaction between the IndentificationCollector and IdentificationPlacer interfaces illustrates the civities that tapping cards on smart car ds. Scanning function operates to validate ID in card and give boolean response indicating valid ID or not, If valid then attendance data will be stored in presence database.

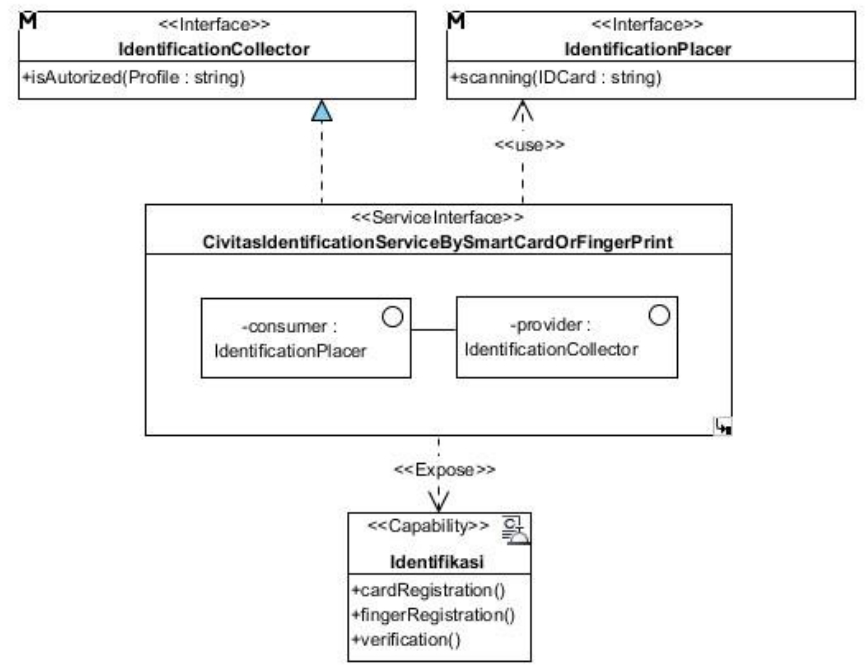

Figure 6 Service interface Identification for Attendance

Figure 7 desrcibes Service participant diagram shows participants as civitas, client sevice and service providers. The identification service has two responsibilities. The first responsibility is to respond to requests from clients requiring civitas profile data and the second responsibility is to include the civitas ID for the presence service.

The profile is sent to the client after the ID of the civitas is received and verified through the web service by performing data based on the ID in the database. When the ID is found, the function will return the data by sending the profile data. This indicates that the ID is valid and registered in the civitas database. The subsequent responsibility of the identification service is to provide a service for attendance. The person ID data of the smart card or finger print is validated with the data contained in the database. If the data is valid then the data will be stored in the attendance database. 
Iwan Setiawan / ITEJ (Information Technology Engineering Journals) (2017) Vol 02- No 02 


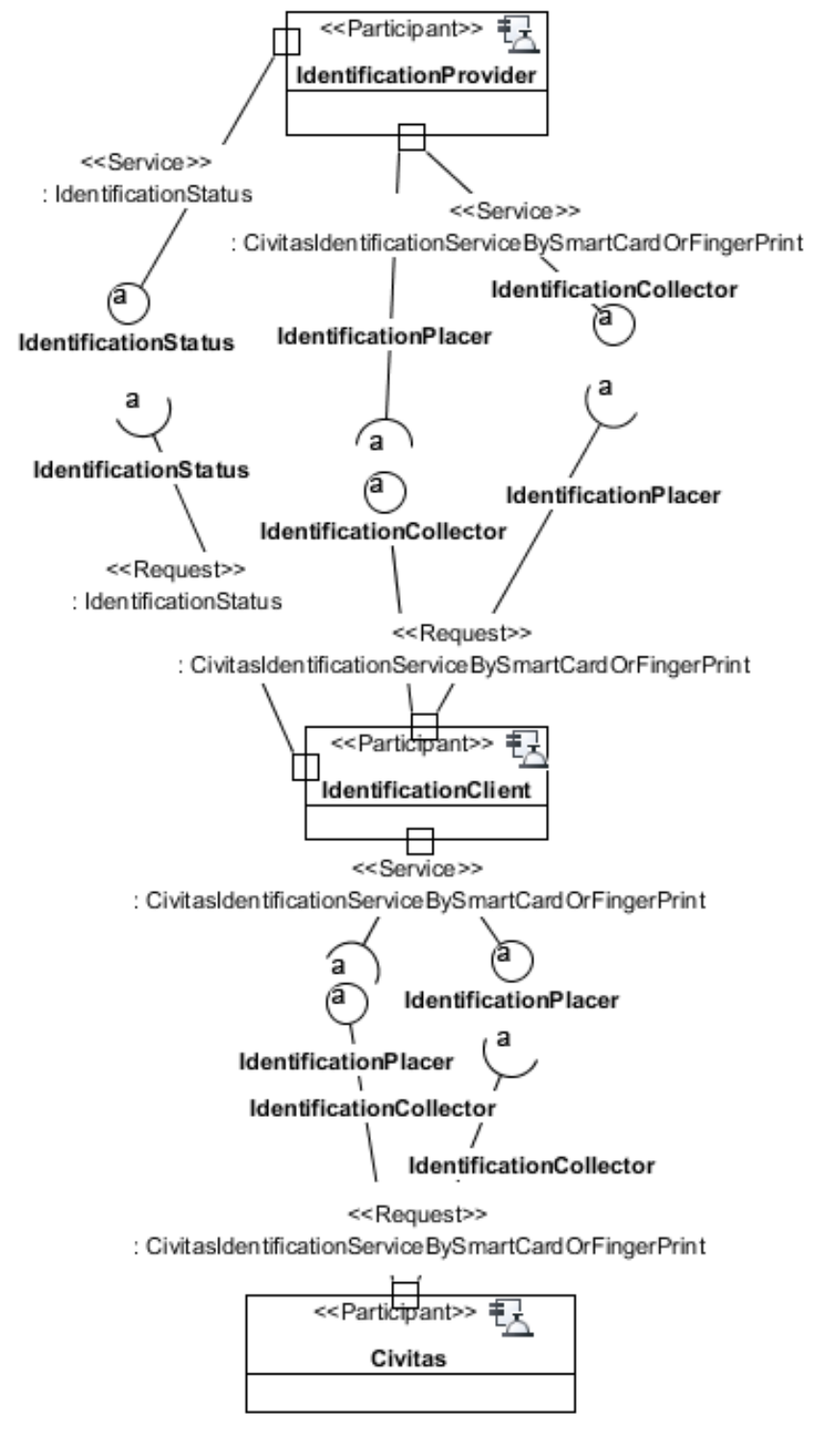

Figure 7 Service participant identification

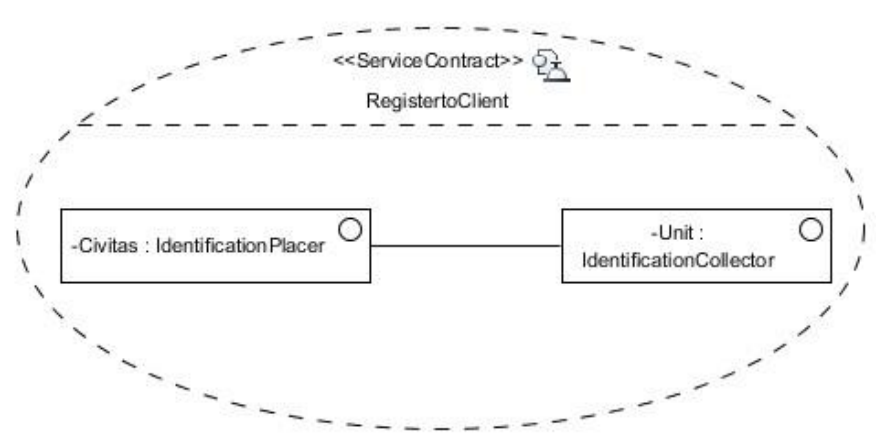

gure 8 Service contract diagram of enrolment to unit
Figure 9 describes the relationship between the provider and the client on the identification service that is illustrated in the service contract diagram. Identification can be done if ID and data have been registered in the database provider and the client has the right of access or authority so that $i \quad t$ can send request to get the data profile.

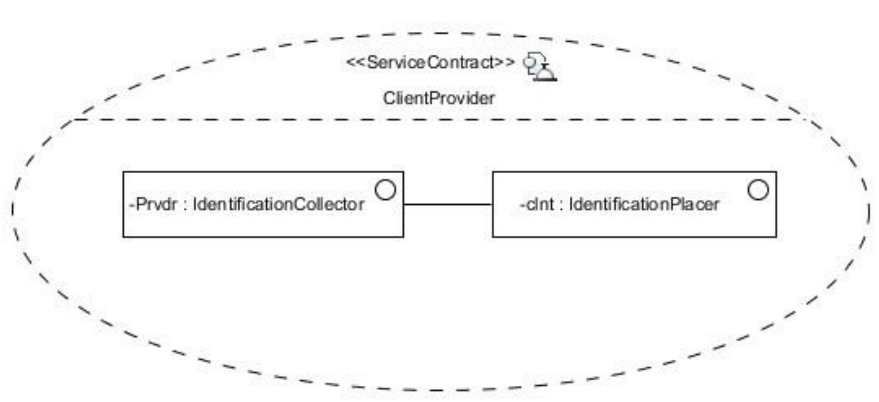

Figure 9 Service contract diagram of client to identification provider

Figure 10 describes the covenant relationship between civitas as attendee and identifier on identification service for attendance system which is illustrated in service contract diagram. Attendee attendance data can be stored in the attendance database if the ID and data are registered in the database as a course participant or lecturer of the course to be followed.

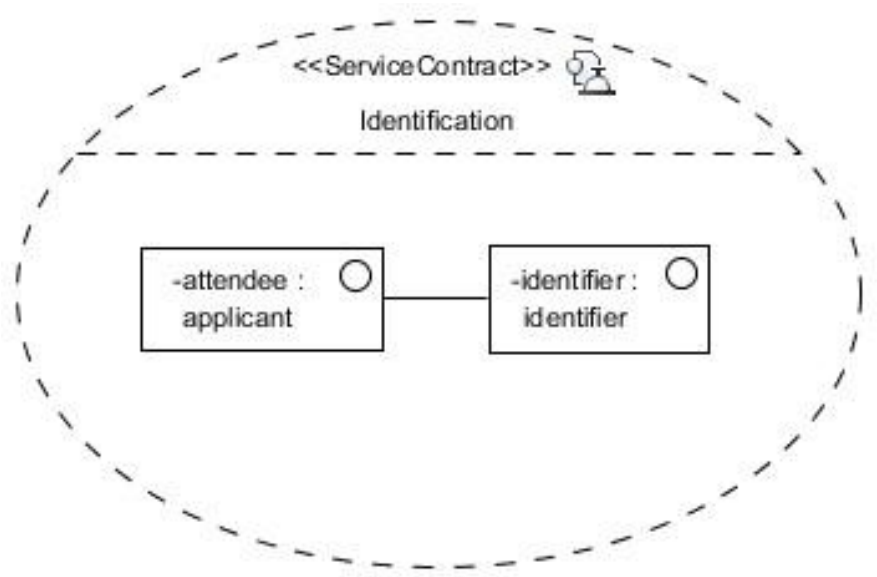

Figure 10 Service contract diagram of identification request

Figure 11 describes the architecture of the attendance system that is illustrate $d$ in the service architecture. In this figure can be seen the relationship between participant. Each participant has its own relationship. The relationship defines the service requested or provided. Register to client (R2C) is the registration service prov ided by the campus unit as the identification user service client provided by the identification service provider. It aims to enable the civitas to register to the unit on campus to get service without having to fill in the registration form. Civitas can $\mathrm{u}$ se the ID they have to register. With the identification service used by the unit on campus allows the request of the civitas data profile to the identification service provider. This can be seen from Client to 
Provide $(\mathrm{C} 2 \mathrm{P})$ in figure $\mathrm{X}$, client or unit as requester of service identification and provider respond to client to send civitas profile data,

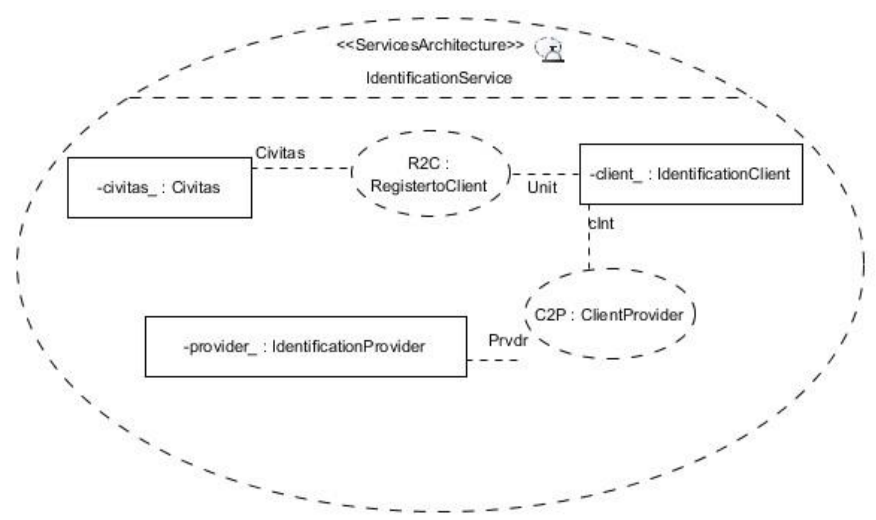

Figure 11 Service architecture diagram of identification service

\section{CONCLUTION AND Future WORK}

Smart Smart attendance is a service that is part of the implementation of people identification. The resulting model of this research becomes a contribution that can be used by universities that will implement or develop the concept of smart campus. Implementation of people identification features not only for smart attendance services. But due to limitations, in this paper only focus on designing smart attendance. Future research is improving the implementation of integrated people identification for the needs of several units within the university. such as for security units, can utilize people identification for people tracking and access control in the university environment. Tracking People can find out the whereabouts of people from campus by monitoring the movement of people through access to places visited by the person in the campus environment.

\section{ACKNOWLEDGMENT}

This research was conducted to fulfill one of the tasks of Design of Information Technology Service course in School of Electrical Engineering and Informatics ITB. Thank you to the Ministry of Communication and Informatics of the Republic of Indonesia for providing Master's scholarships. Thanks also to the Brebes County Government for granting permission to study.

\section{REFERENCES}

[1] W. Muhamad, N. B. Kurniawan, Suhardi, and S. Yazid, "Smart campus features, technologies, and applications: A systematic literature review," in 2017 International Conference on Information Technology Systems and Innovation (ICITSI), 2017, pp. 384-391.

[2] A. Zhamanov, Z. Sakhiyeva, R. Suliyev, and Z. Kaldykulova, "IoT smart campus review and implementation of IoT applications into education process of university," in 2017 13th International Conference on Electronics, Computer and Computation (ICECCO), 2017, pp. 1-4.

[3] T. Erl, Service Oriented Architecture, Concepts, Technology, and Design. Indiana: Prentice Hall PTR, 2005.

[4] M. A. Abas, Auji, and M. Dahlui, "Attendance management system (AMS): Comparison of two different approaches," in 2017 International Conference on Engineering Technology and Technopreneurship (ICE2T), 2017, pp. 1-7.

[5] Chenhao Lin and A. Kumar, "Improving cross sensor interoperability for fingerprint identification," in 2016 23rd International Conference on Pattern Recognition (ICPR), 2016, pp. 943-948.

[6] C. Lin and A. Kumar, "Matching Contactless and Contact-Based Conventional Fingerprint Images for Biometrics Identification," IEEE Trans. Image Process., vol. 27, no. 4, pp. 2008-2021, Apr. 2018.

[7] G. Baldini, G. Steri, I. Amerini, and R. Caldelli, "The identification of mobile phones through the fingerprints of their built-in magnetometer: An analysis of the portability of the fingerprints," in 2017 International Carnahan Conference on Security Technology (ICCST), 2017, pp. 1-6.

[8] D. D. Geralde, M. M. Manaloto, D. E. D. Loresca, J. D. Reynoso, E. T. Gabion, and G. R. M. Geslani, "Microcontroller-based room access control system with professor attendance monitoring using fingerprint biometrics technology with backup keypad access system," in 2017IEEE 9th International Conference on Humanoid, Nanotechnology, Information Technology, Communication and Control, Environment and Management (HNICEM), 2017, pp. 1-7.

[9] A. Purohit, K. Gaurav, C. Bhati, and A. Oak, "Smart attendance," in 2017 International conference of Electronics, Communication and Aerospace Technology (ICECA), 2017, vol. 1, pp. 415-419.

[10] R. Malik, P. Kumar, A. Verma, and S. Rawat, "Prototype model for an intelligent attendance system based on facial identification," in 2016 International Conference on Information Technology (InCITe) - The Next Generation IT Summit on the Theme - Internet of Things: Connect your Worlds, 2016, pp. 40-43.

[11] A. D. Ionita, M. Mocanu, and S. N. Ciolofan, "Modeling with SoaML Applied for Warning and Water Management Services," in 2013 19th International Conference on Control Systems and Computer Science, 2013, pp. 624-627.

[12] A. M. Kosek and O. Gehrke, "Model-driven development of smart grid services using SoaML," in IECON 2014 - 40th Annual Conference of the IEEE Industrial Electronics Society, 2014, pp. 3563-3569.

[13] A. Sadovykh, P. Desfray, B. Elvesæter, A. J. Berre, and E. Landre, "Enterprise architecture modeling with SoaML using BMM and BPMN MDA approach in practice," in 2010 6th Central and Eastern European Software Engineering Conference (CEE-SECR), 2010, pp. 79-85.

[14] K. Finkenzeller, RFID Handbook Fundamentals and Applications in Contactless Smart Card, Radio Frequency Identification and Near-Field COmmunication, 3rd ed. Willey, 2010.

[15] Suhardi, N. B. Kurniawan, M. I. W. Pramana, and J. Sembiring, "Developing a framework for services computing systems engineering," in 2017 14th International Joint Conference on Computer Science and Software Engineering (JCSSE), 2017, pp. 1-6. 